\title{
DEVELOPMENT OF REGULATIONS AND STANDARDS FOR DESIGNING THE TECHNICAL AND VOCATIONAL COLLEGE WITH AN APPROACH OF INTEGRATING THE EDUCATION AND WORK PLACES
}

\author{
Solmaz Namadieslam \\ Faculty member at Sama Technical and Vocational College \\ s.namadieslam@yahoo.com \\ Hamid Lotfollahian \\ PhD student, Gazi University of Ankara \\ hamid_19732002@yahoo.com
}

Sama technical and vocatinal training college, Islamic Azad University,Ardebil Branch,Ardebil,Iran

\begin{abstract}
Nowadays, the psychologists have considered the human evolution as the outcome of personal and environmental interaction. According to this view, the potential talents and abilities are developed in an appropriate environment, and then they are actualized. Therefore, it is very important to pay attention to environmental factors. With regard to motivation of students, there is a need for physical planning to provide new spaces for Technical and Vocational Colleges in order to strengthen and enhance their professional skills; and the integration of work space at college can be an effective step in students' success in different education groups. Numerous conducted studies have only paid attention to design of colleges according to climate and investigated the impact of physical dimensions in educational spaces such as dimensions and proportions, light, color, furniture and arrangement of spaces, etc, or per capita and radii of access to educational spaces. These studies have been conducted in general for all educational spaces, but they are not conducted in particular for all technical and vocational colleges. In this study, a questionnaire is designed for evaluating the impact of workspace at Sama technical and vocational college of Ardabil and distributed among 100 students. The results indicate that most of the students agree with creation of workspace at this college; and establishment of a workplace in the form of workshop and attendance at Sama technical and vocational collage can be a step in development of educational goals and increase in students' creativity and skills.
\end{abstract}

Keywords: Architecture; Integrating the education and work; Technical and vocational

\section{1- Introduction}

The achievement of a proper, comforting and safe, vibrant and joyful educational space and in short a desired educational space requires careful and widespread planning. John Dewey, the famous educations scholar, declares about learners' inner motivations and interest that: "The interest is a spark without which the flame of learning will not be fueled". Any start requires good communication and atmosphere. Teaching-learning process is a two-way trend which needs both parties' agreement. According to Ortson et al, the physical space of classroom should be according to students' characteristics because in this case the learning space can have a positive effect on learners' socialcognitive development. The attention to students' characteristics including the cognitive, social and emotional characteristics in designing the learning spaces can enhance the quality of these spaces and have positive impact on students' development in above-mentioned dimensions.

Nowadays, the education is a source of social changes and innovation. The changed education means doing the plans and procedures in different ways depending on the widespread and diversity in social structure of society. Planning, technology and innovation of ways are new methods and elements which affect changes and improvement of works and their desirability. Education should be as a balance tool among the changes and innovation, and sustainability and stability (Sadri, 2001: 14). 
Given the extensive and broad range of educational system activities, it is necessary to use the most desirable practices in designing and implementing the activities in order to improve the educational quality (Rastegarpour et al, 2009). The ultimate purpose of education is to achieve better learning and this goal will be realized when a basic and principal process is well learned in selecting and providing the educational content for students (Shanmugapriya, 2011).

Barker, the founder of ecological psychology, believes that there is a specific correlation between physical dimensions of architecture and behavioral dimensions in physical bases of behavior. The educational spaces such as classrooms, workshops, etc or the entire educational spaces are considered as the settlements. Benches and their arrangement in a classroom or architecture of educational space, the physical dimensions of architecture, education and all measures in the classroom and college are called behavioral dimensions. (Peaz \& Besable, 1997)

Barker's ecological theory pays attention to social and organized dimensions of settlements, and it is argued that anyone plays certain social roles in physical behavioral settlements. Meanwhile, the systematic social laws and regulations indicate that which behavioral models are provided with time spaces by people in different social roles (Habibi, 1999).

It should be noted that how learning occurs basically. Certainly, our conception of good learning should be along with criteria which cannot be achieved without previous plans. How can be along with learning, but we do not have any plan to reach it? The choice of appropriate and constructive plans will lead to the growth of learning and its desirability. The learning loss will lead to the students' loss in educational periods, and the lack of correct choice of courses, course repetition, nonachievement of science generation and finally the basic human backwardness are all the side problems of absent appropriate plans in education.

Most of the educational activities, prepared by teachers for students, include the students' shallow perception (just memorizing and understanding the concepts). In the case of these conditions, how the same shallow educational methods can be implemented for learners who have entered new levels and are faced with some specialized concepts and laws; while the size and complexity of these concepts have also been increased. Therefore, there are often non-stable learning and even shallow learning of these lessons. To achieve an effective education, there is a need for designing which includes the content, subject and approach selection in inside. According to most of the criticisms of traditional design approaches (conventional), these approaches specify the learning objectives, but they are unable to achieve those goals (Sharples, 2010).

In line with educational activities, the interest and motivations are among the most important topics in teaching-learning process because the teachers and students' efforts will be futile without motivating them. In general, if we even have appropriate and principle plan in which the components are well specified and implemented, we will certainly fail without attention to motivation and motivational components in educational design. It should be noted that we should choose motivation as a reason and consider it as educational purpose and a prerequisite for educational activities in designing for learning (Seif, 2006). With regard to students' motivation, there is a need for physical planning in Technical and Vocational colleges to provide new spaces in order to strengthen and enhance their professional skills. The integration of workspace in college can be an effective step in students' success in different fields of study.

\section{2- Research necessity}

Given the young population of Iran, the changed public attitudes towards the past two decades, and some economic and cultural considerations, there is a need to pay particular attention to academic experts' training and development. More study on reveals that there is a significant theme of changes in educational space and integration of learning environment with changes in educational system in today's developing countries, and thus the open educational system based on a flexible educational space provides a reliable, scientific and cost-effective solution compared to conventional educational system.

However, we can achieve some circumstances of spatial quality and evaluate some educational frameworks as well as organizing the change management by an educational space architect and designer by consultation according to a focus on users of educational facilities in change processes. Therefore, we will be ensured that this change of structure is based on the architectural principles and methods and moves towards the educational quality in addition to the improvement of architectural 
quality and enhanced spatial efficiency. Therefore, we will prevent some changes which occur in certain circumstances.

The educational method, course content, and teaching methods will be changed without change in physics of colleges, so new behavioral models need new physics, spatial communications and regulations which have been less taken into account. Nowadays, the body and spatial communications of technical and vocational colleges have not taken into account only based on the climate, rules and regulations, whereas there is a need for attention to other items such as flexible spaces, designed body proportional to educational content, updated rules and regulations based on the changes, etc along with other factors. The applied strategies have not been effective in integrating the work and educational places for reasons such as wasting students' time in visiting the workplace or passing the unreal training courses, etc; hence, it is necessary to carry out feasibility in some work spaces and seriously add this feature to some educational spaces as well as developing the communications and spatial diagrams and their regulations with other spaces. In some cases, it is necessary to construct the educational spaced in the vicinity of workplaces, so that we should pay attention to their possibility and relevant regulations in their location. Some of the workspaces should be designed in spatial and functional correlation with educational spaces; hence, the applications around these spaces can be effective in this regard, and thus we should develop the regulated types of these applications, and their layout and spatial relations with colleges. Furthermore, the spatial diagrams and technical regulations of building should be revised and redeveloped based on new approaches of integrated work and training spaces. Therefore, the training managers not only will be able to integrate more educational spaces with workplaces, but they also help the students to gain new experiences from work place by creating jobs at colleges, and thus they will achieve the new and sustainable sources of funding. The necessity of involving all stakeholders including students, professors, employers, and educational managers in any physical and non-physical changes is among the requirements without which the proposed cases will not be successful. There is a need for location-based strategies and regulations in this field at various urban scales, surrounding land use and spatial diagrams of technical and vocational colleges. We should investigate the feasibility of implementation methods and funding sources of each regulation in order to implement and generalize them to educational spaces of province according to its climate.

\section{3- Problem Statement}

Education spaces are among the architectural environmental areas which play major roles in a community. The role of education is undeniable in development of society. The neglect and ignorance in designing the educational spaces have led to undesirable results in numerous countries (Karimi, 2001). However, the physical space of educational buildings has remained unchanged, and physical changes have been only limited to restoration of these spaces. Therefore, the created optimal models of spatial connections for technical and vocational colleges based on integration approaches of work and education places can create the attention to climate-friendly design and physical dimensions and characteristics in students' learning and also provide the connectivity and spatial dependencies of work and educational spaces at different urban places, neighborhoods and educational buildings. The educational and work places can be more integrated by the optimal location of technical and vocational colleges in the field of workplaces and intermediary organizations and also favorable educational per capita at the urban level; and by offering favorable model and type of land use arrangement around technical and vocational colleges at the local scale; and proposing the spatial diagrams and arrangement of educational spaces with each other, sizes, infrastructures, etc at minor scale of college structure.

Most of the efforts and conducted studies have been on changed curricula based on market needs or changes in teaching staff, setting up apprenticeships, and visiting the workplaces, which take much time of students, and the need to change some laws and regulations, and so on; so that most of the colleges and workplaces have been independent of each other and tried to integrate them together regardless of spatial dependencies and location-based strategies, while they have neglected the spatial association of educational places with workplaces, particularly revision of spatial connections and design of educational spaces based on these new models. On the other hand, most of the conducted studies have paid attention only to design of colleges according to climate or study on the effect of physical dimensions of educational facilities such as dimensions and properties, light, color, 
arrangement and spaces, etc, or the per capita and radii of access to educational spaces. These studies have been conducted in general on all educational spaces, and in particular on technical and vocational colleges. Furthermore, great effort has also been taken to change the educational programs according to new approaches based on labor market needs, and they have referred to the need for intermediary organizations of educational and work places.

\section{4- Research objectives \\ 4-1- Overall objective}

Development of criteria for designing the architecture of Sama Technical and vocational colleges based on an approach of integrating educational and work spaces

\section{4-2- Specific objectives}

- Identifying the strengths and weaknesses of existing technical and vocational colleges on the basis of new approaches to integrate work and educational spaces;

- Feasibility of integrating the work and educational spaces through spatial strategies in various urban regions, the surrounding land uses and structure of these college;

- Identifying the damages and opportunities for integrating the technical and vocational colleges with work places through spatial strategies and finding that these strategies are suitable for which disciplines;

- Offering the optimal models for spatial diagrams in architectural design of Sama technical and vocational colleges based on approaches for integration of educational and work places in several disciplines such as architectural drawing;

- Survey of students and utilizing their full participation in developing an optimal model of integrating the educational and place;

\section{5- Research hypotheses}

What characteristics should have the architectural design criteria of desired models in Sama technical and vocational colleges based on new approaches to integrate work and educational places, and how they can be developed?

What are the rules and requirements of per capita, adjacent land use, size, infrastructures, safety and other laws of Sama Technical and vocational colleges to implement the approaches of integrating the educational and work places?

How the feasibility of implementation and sources of funding are met for each spatial strategy?

How are the desirable models of spatial diagrams for structural architecture of Sama technical and vocational colleges?

\section{6- Research methodology}

\section{6-1- Type of study, method and conduct of research:}

A range of qualitative and quantitative research methods will be used according to various objectives and aspects of research.

\section{6-2- Data collection tools}

The documentary study, field observation, qualitative interviewing, focus group discussion with audiences and eventually survey through a questionnaire are among the data collection methods in this research.

The information of this study is based on the study of books and articles and conducted research on relevant fields. The theoretical and library studies have tried to investigate the factor affecting the educational success on addition to physical spatial causes which are effective in educational success.

\section{6-3- Statistical population, sample size, sampling and data analysis methods}

Spatial diagrams and the way of connection are extracted by technique of comparable design which is among the qualitative research methods. The stages of comparable design technique include the selection of Sama technical and vocational colleges in province and assessment of their strengths and weaknesses based on the approach of integrating the educational and work places, the typology of samples, extraction of connections, and spatial diagrams at town, district and surrounding land uses and building. Furthermore, the participatory approaches are used to assessment and provide models. 
Sampling has random cluster method. The interviews are designed and implemented by open and exploratory way. Data is analyzed by questionnaires or interviews in the form of descriptive and inferential analyses and through parametric and nonparametric statistics by SPSS software. In spatial analysis, the database is designed for Sama technical and vocational college, and ARC GIS software is operated for analysis, and finally the comparative methods are utilized to provide the rules and regulations in design the architecture of optimal models.

\section{7- Discussion}

The identification experience and analysis of different dimensions of plan are among the basic principles of architectural design. In this regard, the main principles including the environmental communication function are among the main constituents of plan.

\section{7-1- Studies of plan site}

\section{7-1-1- topographical features}

The study on topographical map indicates that Ardabil city is located in Ardabil plain with width of $80 \mathrm{~km}$ and height of 1200 meters above sea level. This plain is surrounded by high mountains and the more we go from downtown to margins, the more the height of region is increased and this increase becomes more especially in the west of city.

\section{7-1-2- Building direction}

The building direction naturally plays a crucial role in providing some of the thermal requirements of interior spaces. The minimum solar energy in warm seasons and maximum solar energy in cold seasons and avoiding the direct penetration of sunlight to building in warm seasons are among the main objectives of designing in appropriate building direction. Therefore, we should investigate two very important factors called the wind blowing and sunlight systems.

The building direction in east-west direction is appropriate in order to use the dominant summer east wind. To prevent the prevailing winter wind, which has southwest direction, the smaller side of building should be in this direction and we should not embed openings in this part of building.

According to the obtained energy of sunlight in southern walls, it can be concluded that these walls gain less energy in summer, and they release more solar energy in winter. Therefore, the building is facing south, and the important spaces of building in this direction. The southeast and southwest walls are more exposed to sunlight in winter than summer and these walls are very important for this climate.

According to the above-mentioned cases, it can be concluded that the building has east-west direction and is facing the east-south.

\section{7-1-3- Natural ventilation based on the climate}

Given the heat conditions of summer weather in these areas and their correlation with bioclimatic building table curves, it is found that it is possible to control indoor air by selection of proper building materials. Furthermore, the mechanical ventilation should be used for ventilating the inside air in cold months of winter.

\section{7-1-4- Appropriate selection of materials based on the climate}

Materials selection depends on two factors namely the thermal capacity and resistance of materials. Olgyay and Givoni's methods are utilized to determine the features of required materials in cold climate.

Olgyay's method: In cold regions, the thermal resistance of materials should be increased and the western walls and interior parts of building should be built by heavy materials in order to maintain favorable conditions in interior of building.

Givoni's method: In cold regions, the building materials should be taken into account by considering two factors namely the outdoor crisis situations and the optimum temperature. The main objective is to keep the heat inside of building in cold regions; and the thermal resistance of side walls is the main factor in this case. Therefore, the side walls of building should have good thermal resistance to prevent wasting the interior heat of building.

\section{2- Trends}

The technical and vocational courses have reflected the students' need to practical training and basic education. In other words, the National Council for Vocational Training in England and Wales has offered GNVQs (General National Vocational Qualifications and NVQs (National Vocational Qualifications). 
If training is not applicable in workplaces with adequate supervision, the colleges must provide real workplaces to assess potential students after interview, so that the current skills should be developed through experience as it is called the Prior Learning Assessment (APL).

It is recommended that the number of teaching/learning work spaces should be based on the efficiency according to the use of optimal planning systems and common principles. For instance, it is assumed that acquiring the efficiency of $40 \%$ is possible in educational space through 40 hours of weekly training, and this needs 2.5 workspaces.

When the number of workspaces in different teaching/learning groupings is calculated, the net and proper level of standard workspace will be created and it will be along with an extra percent for non-educational/non-learning needs and other cases.

The total area (gross) includes the following cases:

- Almost 60 percent for teaching/learning area

- Almost 15 percent for non-educational/non-learning area

- Almost 25 percent for other cases

Fulfillment of educational needs: The fulfillment of educational is among the most important case in all constructed area in each institution and consists of general and specialized training.

\section{7-3- Planning for fulfillment of needs}

\section{7-3-1- Grouping the needs}

Traditionally, the fulfillment of educational needs consists of four main needs: educational/learning, non-educational, non-learning, and other cases. However, in terms of flexibility and adaptability, it is suggested more overlapping between them. The overall space of different grouping is calculated based on the number of student full-time equivalent (SFTE) using different guidelines for principles in different work categories.

Table 1: Per capita educational space

\begin{tabular}{|c|c|}
\hline Type of work space & $\begin{array}{c}\text { Work space } \\
\text { (square meters) }\end{array}$ \\
\hline Basic training & 1 \\
\hline Auditorium, with close-up seat & $1.8-2.1$ \\
\hline At-desk education in unofficial groups & $2.3-2.5$ \\
\hline $\begin{array}{c}\text { Typical desk training/ desk training with performance } \\
\text { education }\end{array}$ & $2.5-3.00$ \\
\hline Students education at big desks & $2.7-3$ \\
\hline Small-scale specialized education & $3.0-4.6$ \\
\hline Information Technology (Commerce) & $3.2-5.6$ \\
\hline Science (non-advanced) & \\
\hline Art and design & $4.5-5.6$ \\
\hline (Studios and design bureaus) & $6.5-8.4$ \\
\hline Domestic economy / trade including carpentry, plumbing, \\
electronics, etc. & $7.5-8.4$ \\
\hline Catering, healthcare & 2.5 \\
\hline Heavy industry (building - welding - repairing engines) & 3.0 \\
\hline Learning & \\
\hline Library / Resource center & \\
\hline Project terminal room if it is appropriate & \\
\hline
\end{tabular}

\section{7-3-2- Changing the educational needs}

\section{7-3-2-1- Growing demand}

There is a tendency towards higher education in all developed countries.

The educational courses are performed by various ways, for instance, by the help of information technology, separate learning programs, more detailed planning, more daily, weekly and yearly work hours. This demand should be fulfilled in stronger and more flexible and adaptable buildings.

For fulfillment of non-educational/non-learning needs, the areas for personnel, administration, catering, common areas, student support services with growing importance, services, restrooms and 
toilets, and warehouse, the sizes of rooms are selected according to sizes of selected groups after calculating the total area.

The approximate sizes of rooms for target groups are carefully studied, and there always has been a wider range of sizes and also smaller groups than teacher's imagination. We should avoid designing spaces for just an application. There should be minimum numbers of lecture stairs halls. The building users should be encouraged to take care of space and facilities because if there is constant control, it will possible to make next changes and obtain more demand.

\section{7-3-2-2- Summary of project}

The project summary process should not be quickly led to definitive solutions, but it should raise questions to keep pace with progress. Similarly, the architect should enter into dialogue with users and also the surrounding population as much as possible. It is not useful to prepare the project summary by an anonymous consultant.

\section{7-3-2-3- Project Management}

Due to the project progress under an advisory committee composing of academic, social, physical and financial parties, there should be a certain decision-maker who controls the monetary affairs.

\section{7-3-2-4- Investment appraisal}

There should be an approximate appraisal of total expected expenditure of new buildings including the current and maintenance costs. There should be the monetary committees which control the loan processes and the institutes which provide an approach to fulfill the needs according to the changed numbers of students, new educational courses, and educational methods for investment in project along with a long-term appraisal of investment with highest value.

\section{7-4- Project advances}

- The location and buildings should be developed in a way that the business contacts are easily applicable between various facilities.

- We should cover the departments which need a center for different spaces to share together and allow departments to carry out or develop their activities using these shared spaces at lower time.

- We should avoid planning and scheduling the rooms with only an application.

- The rooms should be grouped and specific tasks should be provided through furniture and service with easy alternative power in order to provide alternatives.

- Ensure that the buildings have suitable rooms with different sizes for various educational groups at different training courses with various training methods.

- Dividing the planned activities throughout the hours of day, week, semester and year so that the maximum unnecessary concentration of activities is avoided. Remember that the hours of activities in non-educational areas can have an important effect on plans.

\section{7-5- Summary}

Due to the constantly changing nature of educational process variable and the need for buildings, which are able to fulfill the students, personnel, state, and industrial needs, the college designers should reconcile a series of creative tensions.

\section{$\checkmark$ Centralization and non-centralization}

At what stage should we make decision? If funding is done by central authorities, whether users of buildings are considered in their design? Does a firm have much commitment to building by its monetary capital?

\section{$\checkmark \quad$ National standards and individual needs}

The use of spatial criteria should be retained for detailed design works, but they should not be too detailed to prevent new procedures.

\section{$\checkmark \quad$ Long-term and short-term}

The buildings should be taken into account for themselves and their long-term goals, but students use them only for short time use. The administrative and academic staff may use such these buildings for 20 to 30 years. The designers should consider the flexibility of short and long-term attendance in order to meet these broad models for individual attendance.

\section{$\checkmark$ Independence and cooperation}


In new free market, there is a risk that the temporary and unusual subjects are excluded from curricula along with concentration of institutes for attracting the students and more money. Designers need to be sure that the institutes are able to supply their choices for students.

\section{$\checkmark$ Trade, education and education;}

There is a risk that some institutes are more involved with monetary issues, so that the education goes backward compared to business issues and short-term industrial programs. The first educational task of a building should not be forgotten.

\section{$\checkmark$ New experience and technologies}

The teachers, especially in professional sector, may have industrial affiliation, but they may not be aware of modern techniques. The buildings and facilities should provide spaces where the experienced professionals do their best for students.

This research designed a questionnaire for assessing the impact of creating the workplace in Sama technical and vocational college in Ardabil and distributed among 100 students.

The results of statistical analysis are as follows:

1- 100 students $(100 \%)$ were satisfied with study and real work education at the University.

2- 82 students $(96.5 \%)$ agreed with a space to work at Sama University in order to improve students' skills.

3- 75 students (88.2\%) thought that work space at university would attract students' participation in the team working.

4- 84 students $(98.8 \%)$ had this idea that teaching the work and education at university would increase the incentive to continue education.

5- 81 students $(95.3 \%)$ had this idea that the integration of theory with work space at university would increase students' recognition of workspace.

6- 76 students $(89.4 \%)$ had this idea that the new approach of integrating the work with training would improve the quality of teaching space.

7- 79 students $(92.9 \%)$ were in favor of integrating work with training at universities in order to create a context for young people's employment in their countries.

8- 73 students $(85.9 \%)$ had this idea that the integration of work and education spaces at university would attract more students to university.

9- 76 students (89.4\%) agreed that integration of work and education would help to understand more of jobs.

10- 81 students $(95.3 \%)$ agreed that creation of real workplace at university would provide impression of workplace and experience.

11- 78 students (91.8\%) agreed that creating workplace at university would create more familiar with professional tools.

12- 79 students $(92.9 \%)$ thought that creating workspaces at university would cause mental preparation in students outside of university and in their jobs.

13- 78 students $(91.8 \%)$ had this idea that creating workspaces at university would implement doing activities with teacher.

14- 81 students $(95.3 \%)$ agreed that creating workspaces at university would lead to more recognition of students in terms of their interests and skills in profession.

15- 77 students $(90.6 \%)$ agreed that creating workspaces at university would increase the student's ability to solve problems in the workplace.

16- 81 students $(95.3 \%)$ stated that working at university would enable the student to acquire skills and high precision at work.

17- 81 students $(95.3 \%)$ had an idea that the business insurance for students experiencing working at university would create incentives for their skills and ensure their work future.

18- 77 students $(90.6 \%)$ agreed that the designed university space by new approach could be a step to enhance students' creativity and ability.

19- 74 students $(87.1 \%)$ agreed that the design of university spaces by new approach could increase understanding of various technical professions.

20- 43 students $(50.6 \%)$ had this idea that the university could increase the students' creativity without establishing the workspace in education.

According to results, most of the students agree with establishing the workspace at college. Therefore, the creation of workspace in the form of workshop and attending Sama technical and 
vocational college can be a step to progress of educational objectives and increase in students' creativity and skills.

\section{CONCLUSION}

The status of technical and vocational colleges, removing the restrictions and making any necessary modifications at colleges and community are among the necessities. Obviously, the current limitations can be overcome by taking measures for improving the status quo by college authorities as well as considering the approaches to develop the status of technical and vocational education in community as well as mechanisms for optimal use of graduates by governors in their macro and micro decisions. According to educational experts, the efficiency of these modifications, on the one hand, depends on development of infrastructures facilitating the technical and vocational measures in community as well as promoting the quality of belief and mentalities in society about increasing importance of technical and vocational education in sustainable development, and on the other hand, depends on taking intelligent measures in women's participation as the precious human capital in any society. The set of decisions by authorities at colleges and also the governors should have the qualitybased, vision-based, collective, requirement-based and locality-based principles, and also lead to achievement for girls and boys. Obviously, these decisions and their consequences, the improvement of current status at these colleges, and the college graduates' position can play the effective role in dynamism and fulfillment of needs of industrial, service and agricultural sectors. The evaluation of outcome quality at colleges and then determined status quo are the logical and basic steps in understanding the current conditions, making necessary decisions and creating modifications. However, it should be noted that the evaluation is not the end point, but it is an appropriate starting point for intelligent movement. In fact, the creation of necessary conditions for achievement of this principle (planning based on the evaluation and research results) can lead the technical and vocational education system towards development of comprehensive evaluation system and promise the continuous quality improvement in this system.

\section{REFERENCES}

- Habibi, Seyed-Mohsen (1999), Event life and collective memory: educational space; Soffeh publication, No. 28, pp. 16-21.

- Rastegarpour, Hassan; Beyranvand, Farideh; Kavousian, Javad, 2009, The effect of instructional analysis, design, development implementation, evaluation (ADDIE) model on academic achievement in mathematics.

- Seif, Ali-Akbar, 2006, Educational psychology: psychology of learning and teaching, Tehran: Agah.

- Sadri, Fereshteh, 2001, Ways of increasing the teachers' participation in policy-making, management, planning and technology of education; Isfahan, Department of Education, Isfahan Province.

- Karimi, Abdolazim, (2001), Competition or camaraderie in classroom; Journal of Psychology and Educational Sciences at University of Tehran, Tehran, University of Tehran.

- Neufert, Ernst; Neufert, Peter; 2003, Neufert's Architects' Data; Tehran: Azadeh publications.

- Peaz,Dario,Besable,Nekane, \& Gonzalez, Jose Luis(1997), Social processes and collective memory A Cross Cultural Approach to Remembering Political Events In,Jame W.Pennebaker, Dario Peaz \& Bernard Rime.

- Shanmugapriya , M. Tamilarasi , A., 2011, Designing an m-learningapplication for a ubiquitous learning environment in the android based mobile devices using web services

- Sharples, M. Corlett,D. Westmancott,O., 2010, The Design and Implementation of a Mobile 